\title{
East-West Perspectives \\ on Privacy, Ethical Pluralism and \\ Global Information Ethics
}

Charles Ess, Drury

\section{Introduction: the Manichean Problem}

Information and Communication Technologies (ICTs) are both primary drivers and facilitating technologies of globalization - and thereby, of exponentially expanding possibilities of cross-cultural encounters. Currently, over one billion persons throughout the planet have access to the Web: of these, Asian users constitute $35.8 \%$ of the Web population, while Europeans make up $28.3 \%$ of world users - and North Americans only $20.9 \%$ (Internet World Stats, 2007).

Our histories teach us all too well that such encounters - especially concerning potentially global ethical norms - always run the risk of devolving into more destructive rather than emancipatory events. Specifically, these encounters risk pulling us into one of two contradictory positions. First of all, naïve ethnocentrisms too easily issue in imperialisms that remake "the Other" in one's own image - precisely by eliminating the irreducible differences in norms and practices that define distinctive cultures. Second, these imperialisms thereby inspire a relativistic turn to the sheerly local-precisely for the sake of preserving local identities and cultures.

Hence the general problem: how we might foster a cross-cultural communication for a global ICE that steers between the two Manichean polarities of ethnocentric imperialism and fragmenting relativism?

\section{A Global ICE: Basic Requirements}

This difficulty is not new with ICTs and ICE - but is complicated by the fact that ICTs, most especially the Internet, embed and foster the cultural norms and communicative preferences of their Western roots (see Ess 
2006a, 2006b, 2007b.) By the same token, as Soraj Hongladarom points out, until relatively recently, Computer Ethics have remained largely the work of Western ethicists $(2007,110)$.

But of course, there are sharp contrasts between the basic assumptions underlying Western ICE and those defining world traditions and cultures as shaped by Confucian thought, Buddhism, Indigenous traditions, etc. To begin with, in contrast with the modern Western emphasis on the atomistic individual as a primary reality, many of these traditions understand human beings as relational beings, ones whose identity and reality essentially turns on their relationships with others in the larger community (and, perhaps, nature and/or divinity itself). So Barbara Paterson suggests that in general, "In African philosophy, a person is defined through his or her relationships with other persons, not through an isolated quality such as rationality..." (2007, 157). This means in turn that "African thought sees a person as a being under construction whose character changes as the relations to other persons change." (ibid) This notion of the human subject as a relational being is likewise found in Confucian thought (see Ames and Rosemont 1998, 49).

These irreducible differences thus work to define the differences between cultures - and thereby between individuals as shaped by these cultures. These foundational differences are thereby essential to our identities as cultures and members of cultures. Given that persons and cultures have a basic right to identity (Ess 2006a), this immediately means that we are obliged to honor and foster the irreducible differences that define our individual and cultural identities. At the same time, however, as we seek to develop a global ICE, we must do so in ways that simultaneously foster and sustain a shared ethos or set of ethical practices.

\section{How far ought we go towards "the Other"?}

We must ask still one more question before proceeding to develop a global ICE: How far do we want / need / ought to go to meet "the Other"? This question is central because our responses to it will determine how far we may remain satisfied with an ethics that emphasizes shared assumptions and obligations only - and how far we may be willing, if not required, to take up additional ethical obligations necessary in order to honor and foster the irreducible differences that define our cultural and individual identities.

In the following, I begin to sketch out the characteristics of each of these responses. 


\section{Minimal standards—emphasis on commonalities}

What we can think of as a set of minimal ethical standards for a global ICE emphasize commonalities more than differences for the sake of largely pragmatic economic interests.

These minimal standards begin with what Johnny Søraker has described as pragmatic arguments, i.e., arguments that appeal to our shared economic interests. Such arguments are strong candidates for inclusion in a global ICE, precisely because they largely bypass foundational cultural and political differences (2006). Such arguments seem to work: for example, as a condition of joining the World Trade Organization, China has agreed to the Human Subjects Protections endorsed by the World Health Organization as required for medical research: even though these protections were quite alien to the philosophical foundations of Chinese cultures and earlier medical practices, the economic advantages of WTO membership were too great for China to turn down (Döring, 2003).

Moreover, we may expect a global ICE to include agreements on identical values and standards because globalization-as fueled by ICTs themselves - fosters a cultural hybridization and the creation of "third identities" (i.e., syntheses of two distinct cultural values, practices, beliefs, etc.) that represent precisely a shared, global identity. One of the clearest examples of such a third identity is in the domain of privacy. As a number of commentators have observed, young people in Asian countries-specifically Japan, Thailand, and China-increasingly insist on a Western-like practice of individual privacy, one that directly contradicts traditional Asian notions (see Nakada \& Tamura 2005, Rananand 2007, and Lü 2005, respectively). Clearly, young people in these countries are influenced by their exposure to Western notions of individual privacy: and, insofar as there is an increasingly identical set of understandings and values surrounding notions of individual privacy in both East and West, then we may expect that a global ICE will be able to develop a single, (quasi-) universal set of norms and practices for protecting that privacy.

\section{Maximal standards: resonance}

But insofar as the irreducible differences defining diverse cultures and identities are not eradicated or overshadowed by such hybridizations, we are left with the difficulty of crafting a global ICE that will preserve such differ- 
ences. As I've suggested, to do so depends in part on how far we believe we ought / need / want to go beyond pragmatic relationships that emphasize our shared commonalities - and thus, how far we are prepared to engage "the Other" as Other, i.e., precisely in ways that recognize, respect, indeed foster our irreducible differences.

A central model for encountering "the Other" in this second way is provided by the Japanese Buddhist and comparative philosopher Kitarō Nishida's understanding of resonance. This notion of resonance, we will see, is of interest in part because it represents a notion that is shared between such Western philosophers as Plato and Aristotle, and such Eastern traditions as Confucian, Daoist and Buddhist thought. 


\section{Nishida and resonance}

Nishida draws on the language of German philosophy, emphasizing that to preserve our identities as irreducibly distinct from one another, our relationships with one another always take place across the difference of "absolute opposites" [Entgegengesetzter]. But if only sheer difference defines our relationship - then there will be no connection or unity [Vereinigung]. To describe human relationships as a structure that holds together both irreducible difference and relationship, Nishida turns to the term and concept of resonance. As with its musical definition, a resonant relationship entails a connection that simultaneously sustains the irreducible differences required to keep our identities and awareness separate: "The mutual [gegenseitige] relationship of absolute opposites [Entgegengesetzter] is a resonant [hankyō] meeting or response. ... Here we encounter a unity of I and You and at the same time a real contradiction." (Nishida 1988, 391f.; cited in Elberfeld 2002, 138f. Translation from the German by CE)

As I have shown elsewhere, resonance and an affiliated pluralism are central to the work of eco-feminist Karen Warren (1990) and specifically the information ethics of Larry Hinman (1998). Similar notions of resonance emerge in contemporary political philosophy, most specifically in the work of Charles Taylor (2002) and his notion of strong complementarity (see Ess, 2006c). Such complementarity, moreover, is not restricted to other human beings. We may further seek - or believe ourselves required to seek-such resonance with the larger community, and/or the natural order, and/or perhaps even divinity (so far as we believe divinity to exist). Broadly speaking, the further we understand our interrelationship with "the Other" to extend, the more extensive our ethical obligations will become.

Between Nishida and Taylor, then, we can discern models of resonance and complimentarity for our engagements with "the other"- whether in human, natural, and/or divine form - that insist on preserving and fostering the irreducible differences that define our identities as distinct from one another, while simultaneously sustaining relations that, ideally, foster the flourishing of all.

This understanding of the sorts of harmonies we are to strive for, moreover, guide the ethical and political thought of a range of world traditions, including Aristotle, Confucian thought, African thought, etc. At the same time, this emphasis on harmony is likewise a theme shared by contemporary virtue ethics, ecofeminism and environmental ethics. Hence these notions of resonance, complimentarity, and harmony appear to offer a kind of ethical lingua franca that may serve as common grounds for a global ICE. But again, we will 
also see that the ethical demands and obligations these notions entail go well beyond those that follow from an initial - but minimal - emphasis on commonalities alone, as we seek to foster engagements with "the Other" via ICTs distributed globally in ways that preserve the irreducible differences at work in such resonant relationships.

To see how this is so, I first turn to the possible ways - first in theory and then in praxis - of developing such a global ICE, one that constructs a pluralism constituted by shared ethical norms and values alongside multiple interpretations or applications of these values as refracted through — and thus reflecting and preserving - irreducibly different cultural traditions, practices, etc.

\section{Ethical pluralism West and East}

The difficulty of developing an ethics that works across diverse cultures and traditions is an ancient problem: the ancients in both Eastern and Western traditions have developed often highly sophisticated ways of resolving the apparently conflicting demands between agreement and difference. At the same time, the ancient Western and Eastern solutions in fact closely resemble one another in several fundamental ways.

\section{Ethical Pluralism West: Plato, Aristotle, phronesis and "cybernetic pluralism"}

Both Plato and Aristotle — and subsequently, Aquinas — responded to this complex requirement in at least two key ways. To begin with, Plato develops a view that I have characterized as "interpretive pluralism" (Ess, 2006c). On this view, as elaborated especially in The Republic, we may conjoin shared ethical norms with irreducible differences by recognizing that diverse ethical practices may represent distinctive interpretations or applications of those shared norms. Such differences, that is, do not necessarily mean, as ethical relativists would argue, that there are no universally legitimate ethical norms or values: rather, such differences may mean only that a given norm or value is applied or understood in distinctive ways - precisely as required by the details of a given context as shaped by a particular tradition, cultural norms, and practices. 
Aristotle builds on Plato's teaching in several ways, beginning with his notion of pros hen or "focal" equivocals. Such equivocals stand as linguistic middle grounds between a homogenous univocation (which requires that a term have one and only one meaning) and a pure equivocation (as a single term may have multiple but entirely unrelated meanings - for example, "bat" can refer both to a winged mammal and a wooden stick used in baseball). Pros hen or focal equivocals, by contrast, are terms with clearly different meanings that simultaneously relate or cohere with one another as both point towards a shared or focal notion that anchors the meaning of each. Aristotle uses the example of "healthy" to illustrate his point: " ... the term 'healthy' always relates to health (either as preserving it or as producing it or as indicating it or as receptive of it ..." (Metaphysics 1003b2-4; cf. 1060b37-1061a7). So we could say, for example, that a particular diet is healthy ${ }_{1}$ - and good kidney functioning may also be said to be healthy ${ }_{2}$ : but the two terms are not univocals - that is, they do not have precisely the same meaning. On the contrary: with healthy ${ }_{1}$ we mean that the diet contributes to the state of being healthy - while healthy ${ }_{2}$ means that good kidney function is a reflection of the state of being healthy. At the same time, however, precisely because healthy ${ }_{1}$ and healthy ${ }_{2}$ refer to the same "state of being healthy" that, as a shared focal point, thus grounds their meanings - their differences in meaning are thus conjoined with a coherence or connection alongside these differences.

For Aristotle, our ability to negotiate the complex ambiguities of pros hen equivocals is affiliated with a particular kind of practical judgment, i.e., phronesis. Just as we can recognize and appropriately utilize terms that hold different but related meanings - so phronesis allows us to take a general principle (as the ethical analogue to the focal term ground two pros hen equivocals) and discern how it may be interpreted or applied in different ways in different contexts (as the ethical analogues to the two pros hen equivocals-i.e., that are irreducibly different and yet inextricably connected). But what phronesis thereby makes possible is an ethical pluralism that recognizes precisely that shared ethical principles and norms will necessarily issue in diverse ethical judgments and interpretations, as required by irreducibly different contexts defined by an extensive range of fine-grained details.

In fact, Aristotle's understanding of phronesis and thus of ethical pluralism is intimately connected with a central component of computation-namely, cybernetics. Most of us are familiar with the term - as originally developed by Norbert Wiener - as referring to the ability of computer systems to self-regulate and self-correct their processes through various forms of feedback mechanisms. But we need reminding here that "cybernetics" is derived from Plato's 
use of the cybernetes. The cybernetes is a steersman, helmsman, or pilot, and Plato uses the cybernetes as a primary model of ethical judgment - specifically, our ability to discern and aim towards the ethically-justified path in the face of a wide range of possible choices. So Plato has Socrates observe in The Republic:

... a first-rate pilot [cybernetes] or physician, for example, feels the difference between the impossibilities and possibilities in his art and attempts the one and lets the others go; and then, too, if he does happen to trip, he is equal to correcting his error. (Republic, 360e-361a, Bloom trans.; cf. Republic I, 332e-c; VI, 489c.)

"Cybernetics," then, means more originally the capability of making ethical judgments in the face of specific and diverse contexts, complete with the ability to self-correct in the face of error and/or new information. This is to say, the cybernetes, as a model of ethical self-direction, thereby embodies and exemplifies the sort of ethical judgment that Aristotle subsequently identifies in terms of phronesis - i.e., precisely the ability to discern what general principles may apply in a particular context — and how they are to be interpreted to apply within that context as defined by a near-infinite range of fine-grained, ethically relevant details.

\section{Bridge notions with Eastern thought: pluralism, harmony, and resonance}

These notions of judgment and pluralism are found throughout diverse religious and philosophical traditions - including, for example, Islam (Eickelman 2003) as well as Confucian thought (Chan 2003). Moreover, Rolf Elberfeld (2002) has extensively described how the metaphors of harmony and resonance appear in both Western and Eastern traditions, beginning with Plato's account of the role of music as critical to education in The Republic (401d). The metaphors of resonance and harmony, moreover, are clearly structures of pluralism: that is, these notions explicitly entail structures of connection alongside and in the face of irreducible difference. Specifically, the Chinese term ying (resonance) means precisely "a conjunction [Zugleich] of unity [Vereinigung] and division [Trennung]" (Elberfeld 2002, 132).

Finally, Elberfeld demonstrates that these understandings of harmony, resonance, and a correlative ethical pluralism are also found in both an- 
cient and contemporary Daoism and Buddhism (2002, 137f.) And, as we have seen, the highly influential Japanese comparative philosopher Nishida Kitarō takes up the Japanese version of resonance [hankyō] as key to our knowing one another as human beings.

Hence it is clear that these notions of pluralism and resonance are shared cross-culturally - but, unlike simple commonalities, these notions further include the ability to articulate and preserve irreducible differences.

\section{Pluralism in Contemporary ICE}

Indeed, there are at least two examples of such pluralism operating in contemporary theoretical work, beginning with Terrell Ward Bynum's synthesis of the work of Norbert Wiener and Luciano Floridi in what Bynum calls "flourishing ethics." (2006) Similarly, Luciano Floridi (2006) has developed a conception of what he calls a "lite" information ontology-precisely with a view towards avoiding a cultural imperialism, on the one hand (resulting from unilaterally and homogenously applying a single ethical framework across all cultures), while also avoiding, on the other hand, a merely relativist insistence on a local framework only, one that would thereby remain fragmented and isolated from other cultures and frameworks, as the effort to preserve their irreducible differences would (mistakenly) insist on avoiding all shared, putatively universal norms and values. A "lite" ontology can serve as a shared framework that allows precisely for a pluralistic diversity of understandings and applications of a shared notion of informational privacy, as, in effect, the focal, pros hen notion referred to by specific understandings and implementations of privacy within specific - and irreducibly different-cultural settings.

In addition to strong notions of pluralism in these prominent ICE theories, a number of important examples instantiate pluralism in praxis.

\section{Pluralism in Praxis}

As a first example: Bernd Carsten Stahl develops "critical reflexivity" as a procedurally-oriented approach to ICE, one intended precisely to avoid the Manichean polarities of homogenization and fragmentation that confront any effort to develop ethical norms to be shared across cultures. In doing so, 
Stahl takes up the central difficulties of defining 'emancipation' in a way that would work cross-culturally. This requires a formal approach that emphasizes creating “...procedures that allow the individuals or groups in question to develop their own vision of emancipation or empowerment" $(2006,105)$. Such a procedural approach has the advantage that "the critical researcher will not prescribe certain features that she believes to be emancipatory, but that she gives the research subjects the chance to define their version of emancipation" (ibid, emphasis added, CE).

Such critical reflexivity and its allied procedural approach thereby issues in a pluralism that recognizes and respects the irreducible differences defining individual and cultural identities. Stahl sees such pluralism emerging from the application of this procedural approach to debates regarding government and the democratic uses of ICTs $(2006,105)$. In addition, Deborah Wheeler (2006) documents how women in Jordan have been able to take up ICTs in ways that are indeed emancipatory - where 'emancipation,' as Stahl describes, emerges from the agency of local actors who seek to determine the meanings and practices of 'emancipation' that make sense and work best within their specific cultural frameworks and real-world contexts. Stahl's critical reflexivity and procedural approach to defining central norms such as "emancipation" thus issues here in praxis in "emancipation" as a pluralistic concept, one that allows for diverse interpretations and implementations across different cultures.

Similar examples of pluralism can be noted - e.g., Maja van der Velden's account of how such pluralism may be encoded in the source code of software used by diverse Indymedia groups around the world - such that each group is able to modify the software to meet local conditions and requirements, while preserving its main features (2007). More broadly, I have argued that such pluralism can be seen at work in notions of privacy as defined within Western contexts (using the U.S. and Germany as examples) and Eastern contexts (focusing primarily on China and Hong Kong). Here, the pluralism at work serves to reflect and preserve profound differences between Western notions of the individual as a primary, but atomistic reality, and Confucian notions of the self as a relational being. As we might expect, these differences lead to very different data privacy protections. While limited in comparison with Western rights and protections (that emphasize the importance of privacy rights for individuals as rational autonomies participating in democratic governance), privacy rights and data privacy protections are nonetheless emerging in Thailand, China, and Hong Kong (justified primarily as data privacy protections contribute towards economic development as online commerce becomes increasingly important in these economies). In 
this way, we again see a pluralistic, pros hen structure emerge. Privacy and data privacy protection serve as the ethical focal points towards which both Western and Eastern societies orient their laws - but each society understands and interprets the meaning of privacy and data privacy protection in ways that fit their specific context, traditions, values, norms, practices, etc. (Ess 2006c).

As a last example, Soraj Hongladarom has taken up these apparent conflicts between Western and Eastern conceptions, with particular attention to the Buddhist traditions (Theravadan and Mahayanan) of Thai society (2007). Hongladarom moves beyond the initial contrast between the Western emphasis on the atomistic individual vs. Eastern conceptions of the individual as a relational being (Confucian thought) or, as in Buddhism, as a mistaken belief altogether (one that is, indeed, at the source of human dissatisfaction). Hongladarom draws on Nagarjuna's distinction between the self as an empirical-conventional reality, on the one hand, and ultimate reality on the other: given this distinction, Buddhism is perfectly capable of endorsing and taking the individual self as real-at the empirical-conventional level. Indeed, the Buddhist striving towards Enlightenment (as the dissolution of the "self") requires individual effort and responsibility - manifest, e.g., in the injunction to cultivate compassion towards others (Hongladarom 2007, 118). Hence Hongladarom argues that Buddhist societies such as Thailand have a prima facie reason to protect the privacy of such (empirical-conventional) individuals, especially as part of a movement towards establishing a more democratic society in Thailand. That is, the Buddhist injunction, in which each person is responsible for his or her own liberation, thereby sustains notions of equality and democracy that are at least closely similar to those developed and endorsed in Western societies.

In my terms, there emerges here yet again an interpretive pluralism regarding conceptions of the self and privacy as pros hen, ethical focal points: in such a pluralism, modern Western notions of the self (as an ultimate reality whose privacy is a positive good) and Buddhist conceptions of the self (as an empirical-conventional reality) are understood as diverse interpretations or understandings of focal notions of self and privacy - and thereby as conceptions that may nonetheless resonate or harmonize with one another. Indeed, Hongladarom and I have further argued that this harmony further extends between the Buddhist notion of Attasammapanidhi, of ethical selfdirection and self-adjustment, and Plato's model of the cybernetes, the pilot or steersman who symbolizes a similar capacity for ethical self-correction (Hongladarom \& Ess 2007, xix). Finally, Hongladarom points out that Buddhist ethics closely resemble Western-style virtue ethics and the pragmatic 
ethics of Richard Rorty (1975). Hongladarom's analysis thus identifies and reinforces a further deep resonance between Western and Eastern thoughtnamely, between Western virtue ethics (whether in Socratic, Aristotelian, and/or contemporary feminist forms) and the ethical systems of Confucian thought and Buddhism.

Taken together with the previous examples of privacy East-West, the Thai example again marks out in praxis as well as in theory the possibility of a global ICE- one constituted by shared ethical focal points (i.e., shared norms, values, etc.) that are nonetheless articulated and instantiated in diverse ways as these focal points are interpreted and applied in distinctive cultural contexts.

\section{Emerging Rights / Duties?}

In light of the theoretical foundations and practical expressions of pros hen or focal pluralism in an emerging and genuinely global ICE, what rights and obligations might emerge as we take up ICTs more and more into the fabric of our lives?

I can see three layers of responses to this question.

\section{Irresoluble conflict}

While multiple instances demonstrate the possibility of resolving ethical differences within a pluralistic resonance or harmony-manifestly, not all such conflicts will allow for such resolutions. So, for example, Dan Burk (2007) documents the intractable differences between U.S. and European Union approaches to copyright — with the U.S., property-oriented approach currently dominating over the E.U., author-oriented approach. Similarly, Pirongrong Ramasoota Rananand suggests that the tradition and affiliated customs of the Thai "surveillance state" may succeed in keeping "privacy" an interesting idea, but not a right articulated and defended in law (2007).

\section{Minimal requirements-shared commonalities.}

Again, it is possible to begin our encounters with one another globally via ICTs with the straightforward quest for commonalities, including a set of minimal rights and obligations towards one another, justified at least by shared economic interests (Søraker 2007). What emerges from this approach 
is what Westerners will recognize as familiar but primarily negative obligations: don't violate another person's privacy, right to intellectual property, etc.-by not sharing passwords and/or hacking where you don't belong, copying illegally, etc.

\section{Maximal requirements: meeting "the Other" online}

More broadly, our emerging and global ICE depends very much on how far we want / will / need / ought to go in meeting "the Other" online. Presuming that we seek to meet with and engage "the Other" in a more robust way-i.e., one defined by our willingness to acknowledge not only commonalities but also the irreducible differences that define our individual and cultural identities - we are apparently required to move to a more complex mode of thinking and behaving, one shaped precisely by the structures of pluralism and harmony.

To move in these more robust directions, we can perhaps draw at least initial guidance from the following considerations.

\section{Cross-cultural communication ethics}

Broadly speaking, two of the most important factors of successful crosscultural communication that sustains the irreducible differences defining individual and cultural identities are trust and the ability to recognize and effectively respond to the linguistic ambiguity that thereby allows for a pluralistic understanding of basic terms and norms as holding different interpretations or applications in diverse cultures (Ess and Thorseth, 2006). Such pluralism allows precisely for a structure of both shared commonalities and irreducibly different understandings and practices that emerge from our distinctive cultures: thereby, pluralism and ambiguity are necessary conditions for cross-cultural encounters with one another that preserve these irreducible differences as part of the resonance that describes such engagements. Unfortunately, these dimensions of trust, ambiguity, and resonance may be hindered rather than fostered by online environments (cf. Søraker 2006; Grodzinsky \& Tavani 2007).

Moreover, these elements of human communication finally require the now familiar work of judgment - beginning with judgments as to how far or close one's meaning is understood by "the Other," and in turn, how far one understands the meanings of the Other: even though we may use the same 
word or term, their differences in our diverse cultural settings require very careful attention and judgment to determine whether or not we are sliding into equivocation and mis-understanding. But: earning and sustaining trust, successfully recognizing and comfortably negotiating linguistic ambiguities, and utilizing the needed judgment in establishing and sustaining resonant relationships that preserve our irreducible differences - these capacities are not easily captured in analytical frameworks, much less taught in any formal way. They can, of course, be learned through example and experience with embodied teachers: but this again means that the most important elements of successful cross-cultural communication may not be best learned in the disembodied context of contemporary online venues (cf. Dreyfus, 2001).

\section{Information justice and the cultivation of character?}

Numerous writers have argued the rights-based approaches of the West will not work well in "other" cultures. As we have seen, such approaches emphasize the autonomous individual as distinct from the larger community. Such an approach sharply contrasts with the basic assumptions regarding the individual as a relational being that shape the more communitarian / collectively-oriented cultures and traditions of Africa, indigenous peoples, those countries shaped by Confucian and Buddhist traditions, etc. (Cf. van der Velden 2007, 83). For his part, Hongladarom argues that the more radical Buddhist solution to the problem of protecting privacy is not simply to erect laws and create technological safeguards: it is rather to attack the root cause of our motivations to violate privacy in the first place - namely, egoism and its affiliated greed $(2007,120 \mathrm{f}$.)

\section{Conclusion}

In short, a global ICE that seeks to move beyond shared commonalities (and comparatively negative) requirements will apparently call upon us to take up a range of positive obligations and duties, as these are required if we are to preserve irreducible differences while simultaneously engaging in dialogue with "the Other." Happily, these positive obligations and duties are not entirely foreign to the Western traditions: both ancient and contemporary feminist virtue ethics and ethics of care move us in these directions, as do the 
deontological ethics of Kant and others.

As we work - individually and collectively, and especially cross-culturally to develop a global ICE, part of our response, as I hope I've shown with some clarity, depends on how we respond to a central question:

how far am I prepared to go today-i.e., how well am I prepared to take up relationships with "the Other" that entail not simply comparatively straightforward commonalities and pragmatic agreements,

but further entail the difficult efforts to understand and negotiate ambiguity and irreducible difference, precisely in the name of preserving individual and cultural differences-

perhaps, as Paterson argues, even preserving the environment

where such negotiations will require the skills - learned only slowly and over a lifetime - of judgment,

and the cultivation of compassion and care?

Again, the cultivation of such virtues is not entirely alien to Western traditions: on the contrary, I have argued elsewhere for the necessity of an education that fosters Socratic critical thinking and moral autonomy, as key to moving beyond one's own culture towards a more encompassing understanding of a wide diversity of cultures - a movement captured in Plato's Allegory of the Cave, and further exemplified in our notions of Renaissance women and men who attain multiple cultural, linguistic, and communicative fluencies that allow them to comfortably live and work with "Others" around the globe. Contra "cultural tourists" and "cultural consumers" whose ethnocentrism may only be reinforced rather than challenged by their online engagements, such a Socratic-Renaissance education would further foster, following Habermas and feminism, an empathic perspective-taking and solidarity with one's dialogical partners - including our sister and fellow cosmo-politans (world citizens). Of course, such education aims towards the development of phronesis, the practical wisdom required to negotiate the multiple contexts of ethics and politics, with the goal of achieving eudaimonia, human contentment, and harmony in one's own society and the larger world (Ess 2004, 164). And, in terms that have emerged here, such an education would further highlight the importance of moving beyond pragmatic commonalities and shared economic interests to the pluralism of the cybernetes, the one who is able to discern what ethical course to pursue in a specific context - including the often radically diverse contexts of irreducibly distinct cultures - and who is able to correct her errors when they are made. Resonant with Socratic, Aristotelian, and feminist virtue ethics, such an education would further seek to foster the virtues of compassion and care. Such compassion and care are essential to healing the ruptures that follow 
upon our inevitable mistakes in our efforts to understand, work, and live with "the Other" - most especially as we venture out into new linguistic and cultural settings. Such compassion and care, finally, are essential to building and sustaining the trust essential to all human interactions.

ICTs continue their apparently inexorable expansion throughout the world - meaning, they are taken up by more and more people in diverse cultural contexts and settings. It seems certain that if we are to avoid a homogenous world culture - what Benjamin Barber famously called "McWorld" (1995) - more and more of us will need to take up the moral postures and communication skills of the cybernetes, rather than simply pursuing commonalities, pragmatics, and economic self-interest. Perhaps the dramatic scope and speed of cross-cultural encounters made possible precisely by ICTs might help more and more people recognize the need for such exemplary ethics and cultivation of character: but such hopes, of course, must recognize the multiple ways in which most of our online engagements rather foster the minimal obligations entailed by seeking out simply shared interests and pragmatic commonalities, especially as these engagements are oriented towards easy consumption.

\section{References}

Ames, Roger, and Rosemont, Henry. (1998). The Analects of Confucius: A Philosophical Translation. New York: Ballantine Books.

Aristotle. (1968). Metaphysics I-IX (Vol XVII, Aristotle in twenty-three volumes). H. Tredennick, trans. Cambridge, Mass: Harvard University Press. . (1960). Posterior Analytics, Topica. H. Tredennick \& E. S. Forster, trans. Cambridge, Mass: Harvard University Press.

Barber, Benjamin. (1995). Jihad vs. McWorld: How Globalism and Tribalism Are Reshaping the World. New York: Ballantine Books.

Burk, Dan. (2007). Privacy and Property in the Global Datasphere. In S. Hongladarom and C. Ess (eds.), 94-107.

Bynum, Terrell Ward. (2006). A Copernican revolution in ethics? In G. Dodig-Crnkovic \& S. Stuart (Eds.), Computing, philosophy, and cognitive science. Newcastle-upon-Tyne, UK: Cambridge Scholars Press.

Chan, Joseph. (2003). Confucian Attitudes towards Ethical Pluralism. In Richard Madsen and Tracy B. Strong (eds.), The Many and the One: Religious and Secular Perspectives on Ethical Pluralism in the Modern World, 129-153. Princeton: Princeton University Press. 
Döring, Ole. (2003). China's struggle for practical regulations in medical ethics. Nature Reviews | Genetics 4 (March), 233-239.

Dreyfus, Hubert. 2001. On the Internet. New York: Routledge.

Eickelman, D. F. (2003). Islam and Ethical Pluralism. In Madsen and Strong (eds.), The Many and the One: Religious and Secular Perspectives on Ethical Pluralism in the Modern World, pp. 161-180. Princeton and Oxford: Princeton University Press.

Elberfeld, Rolf. (2002) Resonanz als Grundmotiv ostasiatischer Ethik [Resonance as a Fundamental Motif of East Asian Ethics], in Rolf Elberfeld and Günter Wohlfart (eds.), Komparative Ethik: Das gute Leben zwischen den Kulturen [Comparative Ethics: The Good Life between Cultures], 131141. Cologne: Edition Chora.

Ess, Charles. (2004). Computer-Mediated Colonization, the Renaissance, and Educational Imperatives for an Intercultural Global Village. In Robert Cavalier (ed.), The Internet and Our Moral Lives, 161-193. Albany, NY: SUNY Press.

2006a. From Computer-Mediated Colonization to Culturally-Aware ICT Usage and Design. In P. Zaphiris and S. Kurniawan (eds.), Advances in Universal Web Design and Evaluation: Research, Trends and Opportunities, 178-197. Hershey, PA: Idea Publishing, 2006.

2006b. Du colonialisme informatique à un usage culturellement informé des TIC. In J. Aden (ed.), De Babel à la mondialisation: apport des sciences sociales à la didactique des langues, 47-61. Dijon : CNDP - CRDP de Bourgogne, 2006.

Ess, Charles. (2006c). Ethical Pluralism and Global Information Ethics. Ethics and Information Technology 8 (4: November), 215-226

Ess, C. 2007a. Cybernetic Pluralism in an Emerging Global Information and Computing Ethics. International Review of Information Ethics 7 (September). Draft version online: $<$ http://www.i-r-i-e.net/inhalt/007/11-ess.pdf $>$ . 2007b. "Déclinaisons culturelles en ligne : observation « de l'autre »,»Etudes De Linguistique Appliquée, No. 146 (avril, mai, juin 2007).

Ess, Charles, and Thorseth, May. (2006). Neither relativism nor imperialism: Theories and practices for a global information ethics, Ethics and Information Technology 8 (3), 91-95.

Floridi, Luciano. (2006). Four Challenges for a Theory of Informational Privacy, Ethics and Information Technology, 8(3), 109-119.

Grodzinsky, Frances S. and Tavani, Herman T. (2007) Online Communities, Democratic Ideals, and the Digital Divide. In S. Hongladarom \& C. Ess (eds.), 20-30. 
Hinman, Lawrence. (1998). Ethics: A Pluralistic Approach to Moral Theory. Fort Worth: Harcourt, Brace.

Hongladarom, Soraj. (2007). Analysis and Justification of Privacy from a Buddhist Perspective. In S. Hongladarom and C. Ess (eds.), 108-122.

Hongladarom, Soraj and Ess, Charles. (2007). Introduction. In S. Hongladarom and C. Ess (eds.), xi-xxxiii.

Hongladarom, Soraj \& Ess, Charles (eds.), Information Technology Ethics: Cultural Perspectives. Hershey, PA: Idea Group Reference

Internet World Stats. (2007). INTERNET USAGE STATISTICS - The Big Picture: World Internet Users and Population Stats. Retrieved April 8, 2007, from http://www.internetworldstats.com/stats.htm

Lü, Yao-huai. (2005). Privacy and data privacy issues in contemporary China. Ethics and Information Technology, 7, 7-15.

Nakada, Makoto, \& Tamura, Takanori. (2005). Japanese conceptions of privacy: An intercultural perspective. Ethics and Information Technology, 7, 27-36.

Paterson, Barbara. (2007). "We Cannot Eat Data: The Need for Computer Ethics to Address the Cultural and Ecological Impacts of Computing." In S. Hongladarom and C. Ess (eds.), 153-168.

Rananand, P.R. (2007). Information Privacy in a Surveillance State: A Perspective from Thailand. In S. Hongladarom and C. Ess (eds.), 124-137.

The Republic of Plato. (1991). Translated, with Notes, an Interpretive Essay, and a New Introduction by Allan Bloom. New York; Basic Books.

Rorty, R. (1975). Philosophy and the mirror of nature. Princeton, NJ: Princeton University Press.

Søraker, Johnny. (2006). The Role of Pragmatic Arguments in Computer Ethics, Ethics and Information Technology, 8(3):121-130.

Stahl, B.C. (2006). Emancipation in cross-cultural IS research: The fine line between relativism and dictatorship of the intellectual, Ethics and Information Technology 8 (3: July), 97-108.

Tavani, Herman. (2007). Ethics and Technology: Ethical Issues in an Age of Information and Communication Technology, $2^{\text {nd }}$ ed. New York: John Wiley

Taylor, Charles. (2002). Democracy, inclusive and exclusive. In R. Madsen, W. M. Sullivan, A. Swiderl, \& S. M. Tipton (Eds.), Meaning and modernity: Religion, polity, and self, 181-194. Berkeley: University of California Press.

van der Velden, Maja. (2007). Invisibility and the Ethics of Digitalization: Designing so as not to Hurt Others. In S. Hongladarom \& C. Ess (eds.), 81-93. 
Warren, K. J. (1990). The power and the promise of ecological feminism, Environmental Ethics 12: 2 (Summer), 123-146.

Wheeler, Deborah. (2006). Gender sensitivity and the drive for IT: Lessons from the NetCorps Jordan Project, Ethics and Information Technology 8 (3: July), 131-142.

Wiener, Norbert. (1948). Cybernetics: or Control and Communication in the Animal and the Machine. New York: John Wiley. 